\title{
Dynamic-Bias S-parameters: A New Measurement Technique For Microwave Transistors
}

\author{
Gustavo Avolio, Member, IEEE, Antonio Raffo, Member, IEEE, Valeria Vadalà, Member, IEEE, \\ Giorgio Vannini, Member, IEEE and Dominique Schreurs, Fellow, IEEE
}

\begin{abstract}
We present the first application of the recently introduced dynamic-bias measurement to the acquisition of the scattering (S-) parameters of microwave transistors under largesignal operating conditions. We demonstrate that by properly acquiring and processing dynamic-bias measurements one can derive the S-parameters of a nonlinear device-under test across a time-varying large-signal operating point (LSOP). Interestingly, these time-varying $S$-parameters can be used similarly to conventional S-parameters for characterization and modeling purposes. As compared to similar existing approaches, like those based on pulsed S-parameter measurements, with the proposed technique one can obtain, as result of one measurement, the frequency dependent $S$-parameters at each instantaneous point touched by the LSOP. We report experimental dynamic-bias Sparameters of a $0.15-\mu \mathrm{m}$ GaAs pHEMT and a $0.25-\mu \mathrm{m}$ GaN HEMT.
\end{abstract}

Index Terms - Dynamic-bias, S-parameters, large-signal network analyzer, microwave transistors, nonlinear measurements

\section{INTRODUCTION}

$\mathrm{N}$ ONLINEAR characterization is an important step when dealing with transistors used in the design of microwave circuits like mixers, power amplifiers, and oscillators which typically operate under large-signal conditions. For such a reason, next to the classical $\mathrm{dc}$ and $\mathrm{S}$-parameter transistor measurements, set-ups enabling vector-calibrated measurements under nonlinear operation have been developed in the last twenty years. These systems, like the large-signal network analyzers (LSNA), make use of real-time scopes, harmonic samplers, and mixer-based receivers [1]-[10]. These instruments provide a great deal of information on the device behavior as they allow its characterization in conditions very close to those experienced in real-life applications. Nevertheless, performing nonlinear characterization at microwave frequencies is not always a straightforward task [11]. In case, for instance, of harmonically-tuned amplifiers,

Manuscript received

G. Avolio and D. Schreurs are with KU Leuven, 3000 Leuven, Belgium (email: gustavo.avolio@kuleuven.be). G. Avolio is supported by FWO, Vlaanderen, Belgium.

A. Raffo, V. Vadalà, and G. Vannini are with the University of Ferrara, 44122 Ferrara, Italy one needs to measure and tune at least three harmonics and therefore the maximum fundamental frequency that can be used for continuous-wave (CW) measurements is limited to the instrument bandwidth divided by three. Whereas solutions to perform scalar nonlinear measurements in the mm-wave frequency range do exist [12], today's limit of instrumentation enabling vector-calibrated nonlinear measurements is $67 \mathrm{GHz}$ and therefore the highest fundamental frequency which could be used is around $22 \mathrm{GHz}$. Moreover, for harmonic-tuned amplifiers one is interested in knowing the load-line at the transistor current-generator plane and this is not accessible at microwave frequencies. Among others, an approach to overcome some of these limitations consists in introducing low-frequency measurements in the characterization phase of microwave transistors. Several works addressing this topic have been presented in the last years, including [13]-[19]. In these works, the authors show the benefit of using lowfrequency measurements for different purposes, encompassing characterization, modeling, and design. In this context, we recently proposed the dynamic-bias measurement technique [19]-[21], which combines low- and high-frequency measurements. In [19]-[21] we were driven by the need of extracting models for transistors by using experimental data that reproduced operating conditions as close as possible to those in real-life, but beyond the limitations of today's vector calibrated nonlinear measurement systems. We have shown that this approach can be used in various situations, including modeling of transistors for high-efficiency amplifier design [22] and modeling of transistors' non-quasi static effects [23], [24].

In this paper, instead, we show that by properly acquiring and processing dynamic-bias measurements one can obtain the frequency dependent S-parameters of a nonlinear deviceunder-test (DUT) across a time-varying large-signal operating point (LSOP). Interestingly, these time-varying S-parameters can be used in the same way as conventional S-parameters for characterization, modeling, and design [13], [25]-[27].

The paper is organized as follows. In Section II we discuss how the proposed technique to derive dynamic-bias Sparameters compares to similar existing approaches. In Section III we describe how small-signal S-parameters are derived from dynamic-bias measurements and the associated instrumentation set-up. In Section IV we report dynamic-bias 
S-parameters derived from simulation data of a CAD available nonlinear model on one hand and derived from actual measurements of a GaAs transistor on the other hand. We also show that, in case of a device where thermal and trapping effects are negligible, the dynamic-bias S-parameters coincide with the classical multi-bias S-parameters that are measured with a vector network analyzer (VNA). Finally, we report characterization results for a $\mathrm{GaN}$ on $\mathrm{SiC}$ transistor in Section V.

\section{OVERVIEW OF EXISTING TECHNIQUES}

In this Section we discuss how dynamic-bias S-parameters collocate with similar existing measurement techniques.

Dynamic-bias S-parameters belong to those measurement techniques consisting of exciting a nonlinear DUT with largeand small-signal excitations simultaneously [28]-[35]. In the context of nonlinear high-frequency circuits and devices these techniques are employed to measure, among others, hot Sparameters and pulsed S-parameters.

In case of hot S-parameters [30]-[33], which have laid the ground for the development of the more recently introduced $\mathrm{X}_{\text {-parameters }}{ }^{\mathrm{TM}}$ [36] and S-functions [37], the large- and small- signal excitations are CW signals. The large-signal is applied at high frequency. The small-signal is applied either at the same frequency of the large-signal or at a different frequency [30], [31], [36]. As a result of hot S-parameter measurements one obtains the nonlinear response of the DUT, as for example the AM/AM and AM/PM characteristics, and on top of that a set of power-dependent parameters describing the first-order approximation of the DUT perturbed around a large-signal operating point very close to the actual operating condition. This set of parameters constitutes a very powerful behavioral description of weakly nonlinear DUTs which, for example, interact with other blocks in a mismatched environment. The hot $S_{22}$ [30], [31], [32], for instance, provides information on the DUT large-signal output mismatch. Although these parameters can be adopted in the description of the behavior of any nonlinear device, they are very suitable for mixers, amplifiers, and systems where these circuits are cascaded in.

Pulsed S-parameter measurements [34], [35], instead, are typically used for characterization of transistors experiencing slow memory effects. The large signal excitation consists of bias pulses whose period and duty cycle allow one to control the thermal and traps-occupation states of the DUT. On top of the pulses, a high-frequency tickle is applied to measure $\mathrm{S}$ parameters at that fixed thermal state. The amplitude of the pulses determines the DUT pulsed bias point around which Sparameters are measured. By controlling the pulses' amplitude and keeping fixed the period, the duty cycle, and the quiescent bias-point, one can gather isothermal and isodynamic Sparameters in various operating regions of the DUT [34]. Therefore this technique is very powerful for characterizing dispersive effects as it actually allows to isolate trapping effects from thermal effects. Additionally, if the transistor current is also measured within the pulse duration [34], [38], [39], [40] one can obtain pulsed IV characteristics. On the other hand, a pulsed large-signal operating point is far from actual operating conditions in many high-frequency circuits.

Dynamic-bias S-parameters position in between the two approaches described above. Similarly to hot S-parameter measurements they are derived by driving a nonlinear DUT with $\mathrm{CW}$ large and small excitations. However, differently from the hot S-parameter measurements, the frequency of the large signal excitations is much lower than that of the small signal excitations. This is a clear advantage, since the LSOP of the DUT is determined at much lower frequencies, namely in the megahertz range where hardware limitations, e.g., in terms of power, are more relaxed and instruments' bandwidth is not an issue. On top of such a low-frequency LSOP, the smallsignal excitation is simultaneously applied at the RF frequency of interest. Owing to the small power of the tickle, its harmonics can be neglected [21] and this enables the smallsignal frequency to be set as high as the instrument bandwidth limit. Furthermore, one can straightforwardly set the LSOP very close to the actual transistor operation and exactly at the current-generator plane (e.g., class-F for high-efficiency amplifier). This is not obvious when the LSOP is set at higher frequencies, as is the case of hot S-parameter measurements, since nonlinear reactive effects and linear parasitics mask the actual temporal waveforms at the transistor current-generator plane. Importantly, and differently from hot S-parameters, the low-frequency LSOP represents a slowly varying bias point for the DUT. As a consequence, we do not derive dynamicbias S-parameters as power-dependent perturbation quantities at the tickle frequency. We, instead, derive time-varying $\mathrm{S}$ parameters by obtaining them around all the points of the time-varying LOSP and over the desired frequency range, as explained in Section III in more detail. This, definitely, constitutes an advantage also in comparison to pulsed Sparameters. Clearly, since the LSOP of dynamic-bias measurements is defined both by $\mathrm{dc}$ and low-frequency signals, each time we change it, both thermal and trapsoccupation states do change as well and this represents the main difference with respect to pulsed measurements, where the trapping and thermal states are simply related to the selected bias condition.

In the next Section we explain how to derive dynamic-bias S-parameters.

\section{THEORETICAL BACKGROUND}

As widely known, S-parameters for an active two-port network can be calculated, around a fixed bias-point, by acquiring the network scattered waves as the result of two independent measurements obtained, for example, by applying a small-signal excitation first to port 1 and then to port 2 . From these two measurements one can straightforwardly derive the S-matrix:

$[\underline{S}]=\left[\begin{array}{ll}b_{1,1} & b_{1,2} \\ b_{2,1} & b_{2,2}\end{array}\right]\left(\left[\begin{array}{ll}a_{1,1} & a_{1,2} \\ a_{2,1} & a_{2,2}\end{array}\right]\right)^{-1}$

where the second index indicates the port where the small- 
signal excitation is applied to. The scattered waves $b_{i, k}$ are complex numbers which are unique for a given bias point $\left(\mathrm{V}_{\mathrm{dc}}\right)$ and frequency $\left(\mathrm{f}_{\mathrm{RF}}\right)$ :

$b_{i, k}=\left|B_{i, k}\left(V_{d c}, f_{R F}\right)\right| e^{j\left(2 \pi f_{R F} t+\varphi_{i, k}\left(V_{d c}, f_{R F}\right)\right)}$

In this case, the dc bias voltages set a static operating point. Under dynamic-bias measurements, instead, low-frequency large-signal excitations at $f_{\mathrm{LF}}$ are superimposed on the $\mathrm{dc}$ voltages, thus determining a time-varying [19]-[21], [28]-[33] operating point.

Similarly to the classical small-signal measurements, a tickle at $f_{R F}$ is applied first to port 1 and then to port 2 on top of the time varying LSOP. As extensively discussed in [19][21], if the frequency of the LSOP $f_{L F}$ is much smaller than $f_{R F}$, the LSOP can be assimilated as a slowly varying bias point as compared to the tickle. Moreover, if $\mathrm{f}_{\mathrm{LF}}$ is selected above the cut-off frequency of dispersive effects and it is low enough to neglect reactive nonlinearities [14], the LSOP provides directly the device I-V characteristics at the thermal and trap states set by the LSOP itself.

Since the LSOP acts as a slowly varying bias point, it modulates the amplitude and the phase of the scattered waves at $f_{\mathrm{RF}}$, which can be described by time-dependent complex numbers,

$b_{i, k}=\left|B_{i, k}\left(V(t), f_{R F}\right)\right| e^{j\left(\varphi_{i, k}\left(V(t), f_{R F}\right)\right.} e^{j\left(2 \pi f_{R F} t\right)}$.

If we were able to freeze the envelopes at a certain time instant $t^{*}$, we would reproduce a similar situation as described by (2) but with the bias point $\mathrm{V}\left(\mathrm{t}^{*}\right)$ applied dynamically and not statically. Clearly, if the device behavior manifested negligible low-frequency dynamic effects with respect to the LSOP, S-parameters derived from (1) by using either (2) or (3), should provide the same results, as we will demonstrate in next Section. It is noteworthy that in (3) we refer only to the scattered waves assuming that the tickle applied to port 1 and port 2 is a pure $\mathrm{CW}$ small signal. When performing actual dynamic-bias measurements, intermodulation tones around $f_{R F}$ may appear also in the experimental incident waves due to mismatches between signal sources, measurement set-up, and device-under test. However, this does not affect at all the results as this is accounted for in (1) as in case of standard Sparameters.

In order to derive small-signal parameters under dynamicbias operation, the $\mathrm{CW}$ waves in (1) are replaced by the complex envelopes of the incident and scattered waves (3). These envelopes can be derived from the intermodulation tones induced around $f_{\mathrm{RF}}$ under dynamic-bias operation [19][21] and which are shown in Fig. 1 for illustrative purposes. As result of (1) one obtains an S-matrix which depends on $f_{R F}$ and on the instantaneous dynamic-bias point $\mathrm{V}\left(\mathrm{t}^{*}\right)$ determined by the LSOP.

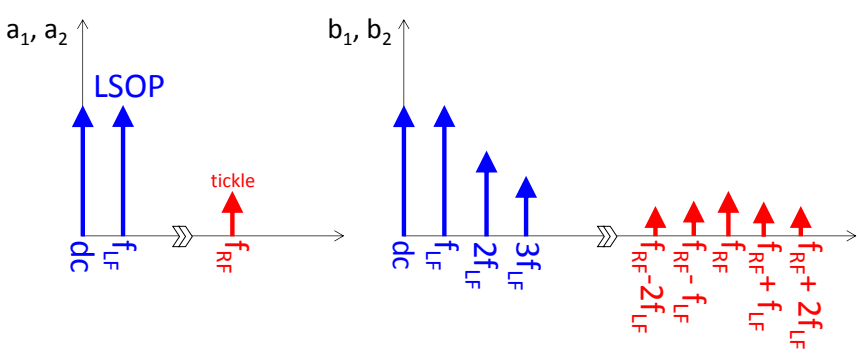

Fig. 1 Frequency spectra of incident and scattered waves under dynamic-bias operation.

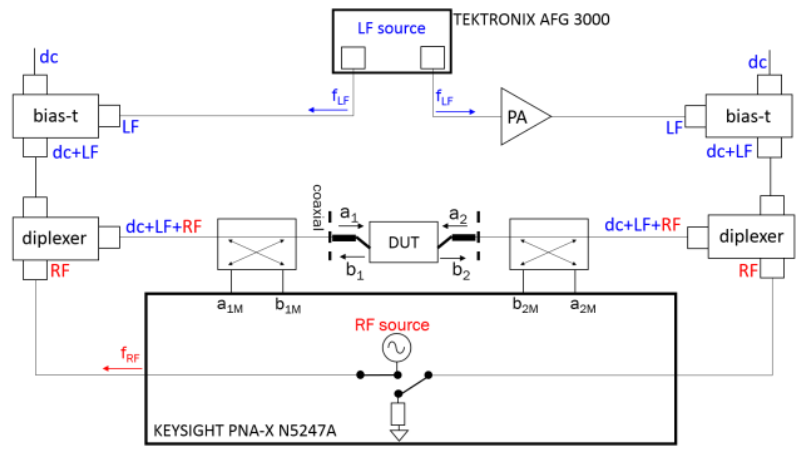

(a)

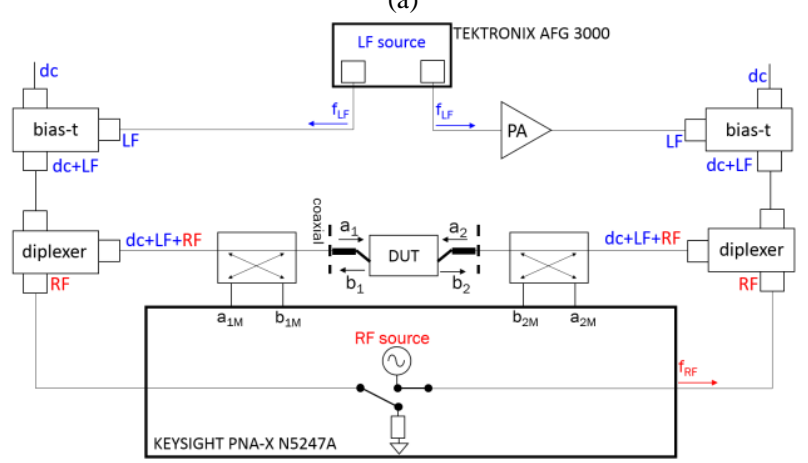

(b)

Fig. 2 Schematic of the set-up adopted to measure dynamic-bias S-parameters. Tickle applied to (a) port 1 and (b) port 2.

\section{CONCEPTUAL AND EXPERIMENTAL VALIDATION}

\section{A. Description of the measurement set-up}

In our previous works we showed a measurement set-up to perform dynamic-bias measurements based on a four-channel high-frequency sampler-based LSNA [4] extended with four additional channels to acquire synchronously also the lowfrequency signals determining the LSOP. In this work we used a $10 \mathrm{MHz}-67 \mathrm{GHz}$ mixer-based LSNA [6], thus being able to measure both the LSOP and the intermodulation tones around $f_{R F}$ with the same receivers. We customized the test-set to perform dynamic-bias S-parameter measurements, as shown in Fig. 2. The couplers in front of the receivers have a high-pass characteristic in order to equalize the frequency components of the signals at the input and output port of the device-undertest and prevent receivers' desensitization due to the presence of the large signals at low frequencies. The coupling factor is equal to $50 \mathrm{~dB}$ at $10 \mathrm{MHz}$ and $15 \mathrm{~dB}$ at frequencies above $1 \mathrm{GHz}$. The diplexers and the bias-tees combine the dc, low, and high-frequency signals at the device-under-test plane. The LSOP is determined by the dc voltages and the low-frequency 
signals injected at the input and output ports. While the LSOP is turned on, a high-frequency tickle is switched between port 1 and port 2, the other port being terminated with a passive load. For each LSOP the frequency $f_{R F}$ is swept, similarly to small-signal measurements performed with a VNA.

The calibration of the set-up consisted of a standard built-in procedure. First, we performed S-O-L, amplitude, and phase calibrations at the coaxial plane (Fig. 2) at the frequencies of interest. Next we moved the reference plane at the on-wafer probe tips by performing a full two-port vector calibration.

\section{B. Validation by simulation and experimental data}

In this Section we aim at demonstrating the validity of the proposed characterization technique by comparing Sparameters obtained under dynamic-bias to classical multibias small-signal S-parameters. For this reason we selected a CAD model and a device-under-test which do not include and manifest any dispersive effect induced by the low-frequency LSOP. This implies that the dynamic-bias small-signal parameters and the classical small-signal parameters have to show the same behavior. In particular, for the simulation we used a CAD available nonlinear transistor model for GaAs pHEMTs [41] implemented by adopting nominal parameter values, whereas for the actual measurements we used a 0.15 $\mu \mathrm{m}$ GaAs pHEMT.

In Fig. 3 we show the simulated LSOP (a) and the dynamic scattering ( $\mathrm{S}$-) parameters (b-d) for the CAD model. The LSOP was set at $\mathrm{V}_{\mathrm{gdc}}=-1.5 \mathrm{~V}, \mathrm{~V}_{\mathrm{ddc}}=6 \mathrm{~V}, \mathrm{~A}_{\mathrm{g}}=0.75 \mathrm{~V}$ and $\mathrm{A}_{\mathrm{d}}$ $=3 \mathrm{~V}$, with $A_{g}$ and $A_{d}$ being the amplitudes of the signal injected respectively at gate and drain ports at $\mathrm{f}_{\mathrm{LF}}=10 \mathrm{MHz}$. The relative phase between $A_{g}$ and $A_{d}$ was set equal to $180^{\circ}$. The power of the high-frequency tickle was set equal to $30 \mathrm{dBm}$ and its frequency $\mathrm{f}_{\mathrm{RF}}$ swept from $1 \mathrm{GHz}$ up to $30 \mathrm{GHz}$. Figures 3b-d show, in particular, the dynamic smallsignal parameters $(1)$ at three dynamic-points $\left(\mathrm{V}_{\mathrm{g}}\left(\mathrm{t}^{*}\right), \mathrm{V}_{\mathrm{d}}\left(\mathrm{t}^{*}\right)\right)$ marked in Fig. 3a. For the same device we report in Figs. 3b-d also the classical small-signal parameters simulated by applying dc voltages equal to those selected on the LSOP. As expected the dynamic- and static-bias S-parameters coincide, confirming the theoretical assumptions we made in the previous Section.

To corroborate the proposed approach, we performed measurements on a GaAs transistor. GaAs technology is known to be very well-established and manifesting very negligible trap-related dispersive effects. Moreover, we selected a device with small gate width in order to minimize thermal effects. The LSOP (Fig. 4a) was applied at $\mathrm{f}_{\mathrm{LF}}=$ $10 \mathrm{MHz}$. The quiescent dc gate and drain voltages were $\mathrm{V}_{\mathrm{gdc}}=$ $-0.6 \mathrm{~V}$ and $\mathrm{V}_{\mathrm{ddc}}=6 \mathrm{~V}\left(\mathrm{I}_{\mathrm{ddc}}=33 \mathrm{~mA}\right)$. The amplitude of the incident wave at $f_{\mathrm{LF}}$ was $0.5 \mathrm{~V}$, whereas the output lowfrequency port was terminated with a passive load. The power of the tickle was set equal to $-30 \mathrm{dBm}$ and $\mathrm{f}_{\mathrm{RF}}$ was swept from $2 \mathrm{GHz}$ to $40 \mathrm{GHz}$. In Fig. $4 \mathrm{~b}$ and $4 \mathrm{c}$ we report the amplitude of the measured envelopes at $\mathrm{f}_{\mathrm{RF}}=10 \mathrm{GHz}$ and with the tickle on port 1 (Fig. 4b) and port 2 (Fig. 4c). The IF bandwidth of the measurements was $10 \mathrm{~Hz}$ to achieve the lowest noise level.

By applying (1) to the measured envelopes at each $\mathrm{f}_{\mathrm{RF}}$, one obtains the S-parameters, as function of $f_{\mathrm{RF}}$, at all the dynamic bias points of the LSOP in Fig. 4a, as shown in Fig. 5.

For the same device we measured also classical multi-bias S-parameters with a VNA and compared them with dynamicbias S-parameters, as shown in Fig. 6. For the device considered in this work, which had a relatively small size, we do not observe any significant difference between the conventional and dynamic-bias S-parameters. However, it is noteworthy that due to thermal effects the two measurements do not have necessarily to agree as the thermal state is clearly different in the two cases.

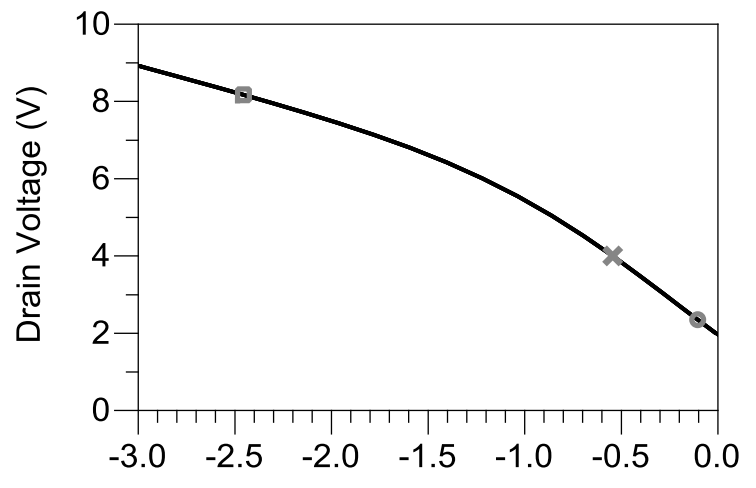

Gate Voltage (V)

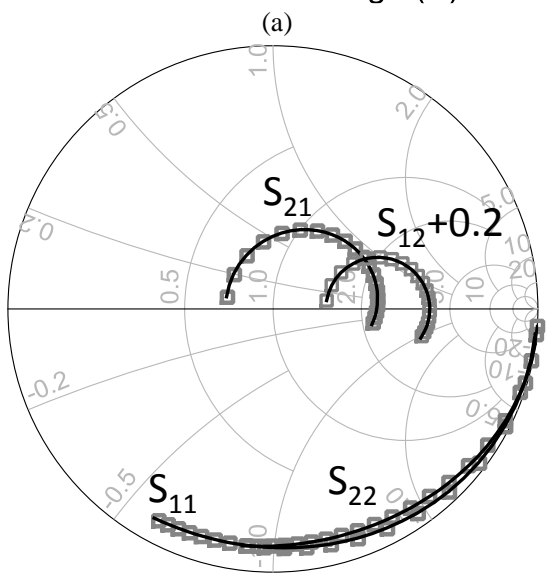

(b)

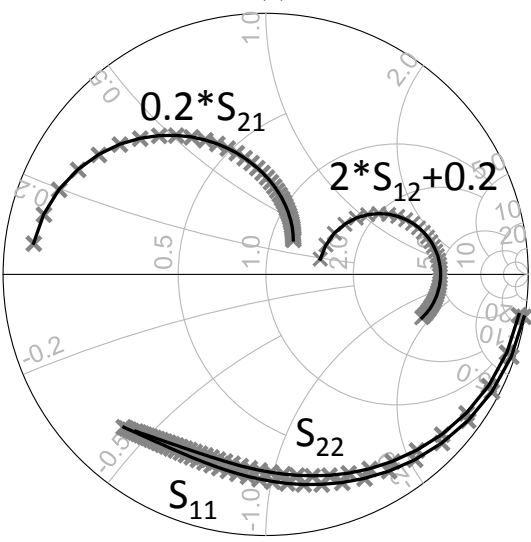

(c) 


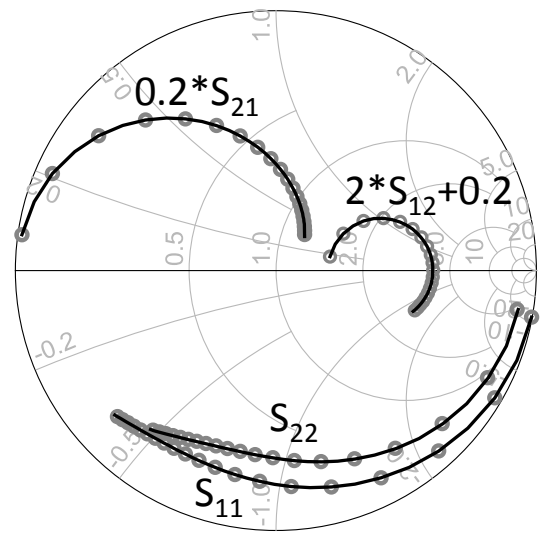

(d)

Fig. 3 Simulated LSOP at $\mathrm{f}_{\mathrm{LF}}=10 \mathrm{MHz}, \mathrm{V}_{\mathrm{gdc}}=-1.5 \mathrm{~V}, \mathrm{~V}_{\mathrm{ddc}}=6 \mathrm{~V}$ (a) and simulated dynamic-bias S-parameters (symbols) from $1 \mathrm{GHz}$ to $40 \mathrm{GHz}$ (b)(d) around the dynamic-bias points which are marked on the LSOP trajectory in (a). Continuous lines in (b)-(d) are the classical S-parameters simulated by setting the dc voltages equal to those marked in (a). We used a CAD nonlinear model [41].

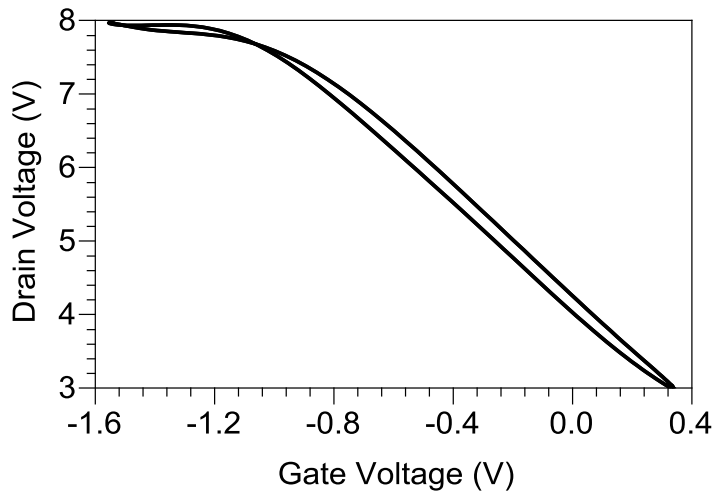

(a)

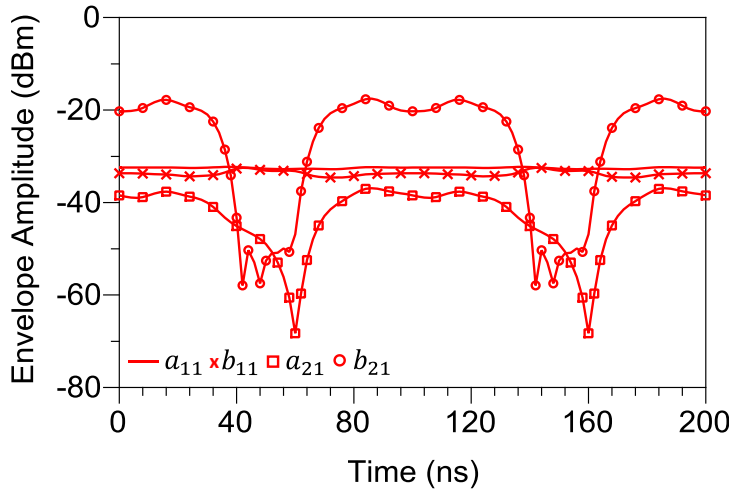

(b)

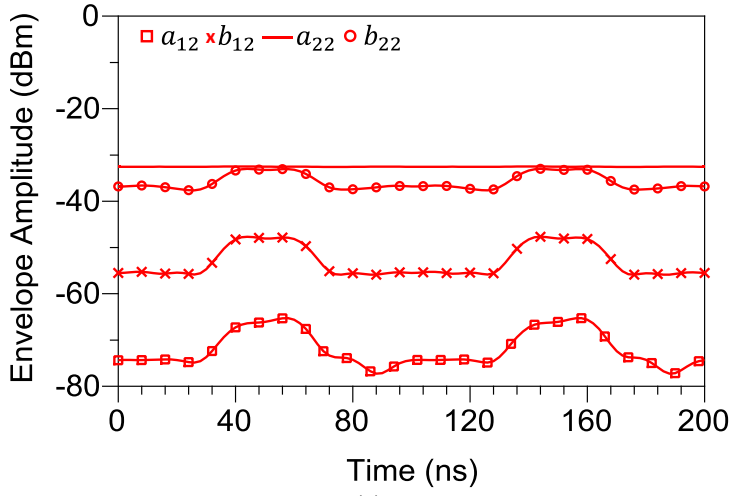

(c)

Fig. 4 Measured LSOP (a) and envelopes around $f_{R F}(b)-(c)$. Envelopes when the tickle $\left(a_{11}\right)$ is applied at port $1(b)$. Envelopes when the tickle $\left(a_{22}\right)$ is applied at port $2(\mathrm{c}) . \mathrm{f}_{\mathrm{LF}}=10 \mathrm{MHz}, \mathrm{f}_{\mathrm{RF}}=10 \mathrm{GHz}, \mathrm{V}_{\mathrm{gdc}}=-0.6 \mathrm{~V}$, and $\mathrm{V}_{\mathrm{ddc}}=$ $6 \mathrm{~V}$. The device under test is a $0.15-\mu \mathrm{m}$ GaAs pHEMT.
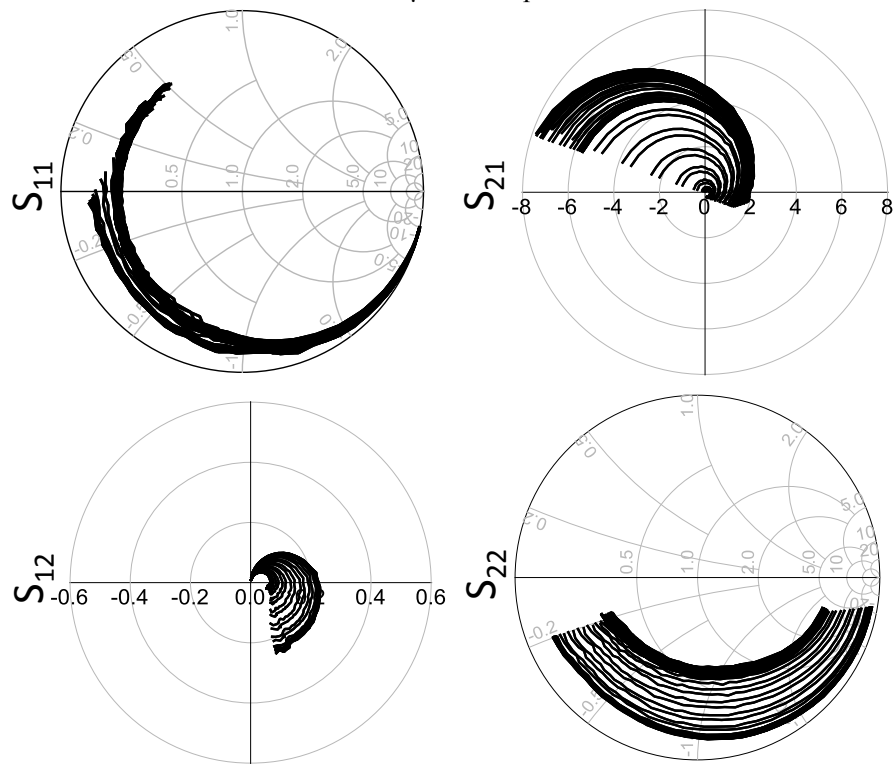

Fig. 5: Measured dynamic-bias S-parameters, derived from (1) and (3) as function of frequency $\mathrm{f}_{\mathrm{RF}}$ from $2 \mathrm{GHz}$ to $40 \mathrm{GHz}$ and for all the dynamic-bias points corresponding to the $\mathrm{LSOP}$ at $\mathrm{f}_{\mathrm{LF}}=10 \mathrm{MHz}$ in Fig. 4a.

\section{Comparison with a sampler-based LSNA}

As we reported in [21], dynamic-bias measurements can be performed also with a sampler-based LSNA. The set-up described in [21] is equipped with eight acquisition channels, four to acquire the low-frequency LSOP and four to acquire the RF part of the frequency spectra. In this work we used also that instrument to measure dynamic-bias S-parameters and compare them with those obtained from the measurements carried out with a mixer-based LSNA and reported in the previous section. The device-under-test was the same $0.15-\mu \mathrm{m}$ GaAs transistor. Moreover, with the sampler-based LSNA we were able to change the frequency of the LSOP, as the lowfrequency receivers enable measurements below $10 \mathrm{MHz}$. In Fig. 7 we compare dynamic-bias S-parameters measured with the sampler-based LSNA at $f_{\mathrm{LF}}=100 \mathrm{kHz}$ to those measured with the mixer-based LSNA at $\mathrm{f}_{\mathrm{LF}}=10 \mathrm{MHz}$. This result demonstrates that dynamic-bias S-parameter measurements could also be performed with a sampler-based LSNA, even though this instrument has a smaller dynamic range as compared to a mixer-based architecture. Indeed, since in case of the sampler-based LSNA the LSOP of the device is measured by separate receivers, the measurement sensitivity of the RF channels is high enough to ensure dynamic-bias Sparameter measurements with acceptable accuracy. In Fig. 7 measurements performed at two LSOP frequencies agree quite well, in line with the expectations for a technology manifesting negligible dispersion [42]. 


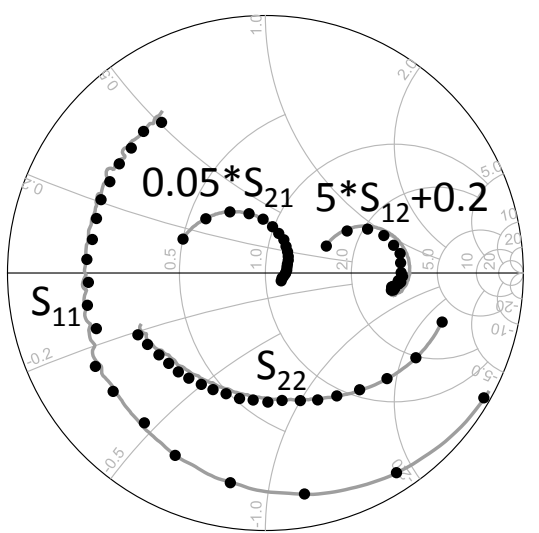

(a)

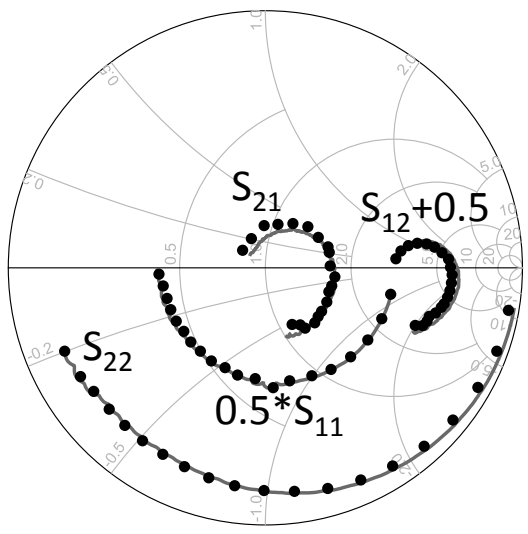

(b)

Fig. 6 Measured dynamic-bias S-parameters (dots) and classical multi-bias (lines) S-parameters for a $0.15-\mu \mathrm{m}$ GaAs pHEMT. The frequency of the LSOP is $\mathrm{f}_{\mathrm{LF}}=10 \mathrm{MHz}$, and the bias point is $\mathrm{V}_{\mathrm{gdc}}=-0.6 \mathrm{~V}$ and $\mathrm{V}_{\mathrm{ddc}}=6 \mathrm{~V}$. The frequency $\mathrm{f}_{\mathrm{RF}}$ of the tickle is swept from $2 \mathrm{GHz}$ to $40 \mathrm{GHz}$. In (a) the dynamic bias point selected on the LSOP (Fig. 3a) is $\left(\mathrm{V}_{\mathrm{g}}=-0.675 \mathrm{~V}, \mathrm{~V}_{\mathrm{d}}=6.69 \mathrm{~V}\right)$ and the corresponding point selected on the multi-bias grid is $\left(\mathrm{V}_{\mathrm{gdc}}=-0.65 \mathrm{~V}, \mathrm{~V}_{\mathrm{ddc}}\right.$ $=6.5 \mathrm{~V})$. In (b) the dynamic point is $\left(\mathrm{V}_{\mathrm{g}}=-1.53 \mathrm{~V}, \mathrm{~V}_{\mathrm{d}}=7.9 \mathrm{~V}\right)$ and the corresponding point selected on the multi-bias grid is $\left(\mathrm{V}_{\mathrm{gdc}}=-1.5 \mathrm{~V}, \mathrm{~V}_{\mathrm{ddc}}=\right.$ $8 \mathrm{~V})$

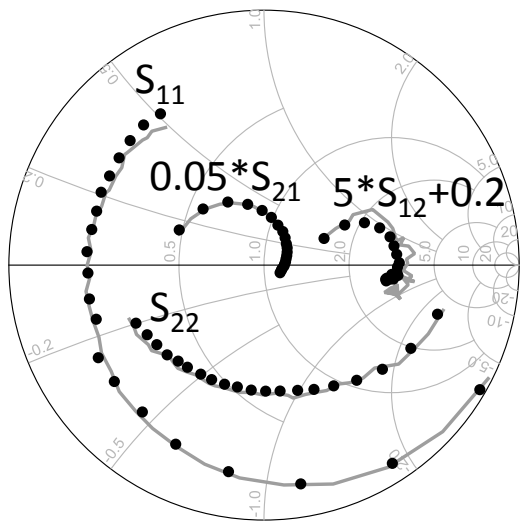

(a)

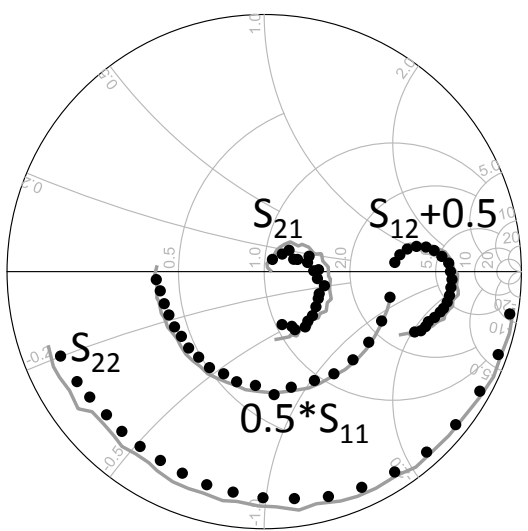

(b)

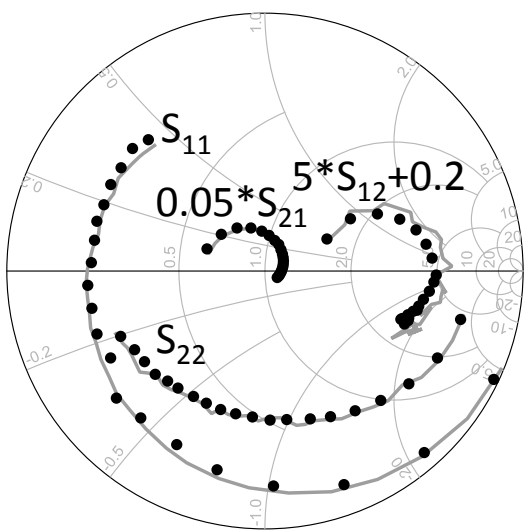

(c)

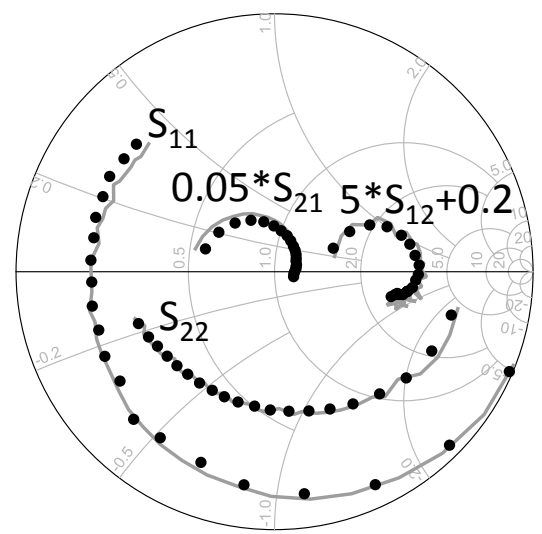

(d)

Fig. 7 Measured dynamic-bias S-parameters for a $0.15-\mu \mathrm{m}$ GaAs pHEMT with a sampler-based LSNA at $\mathrm{f}_{\mathrm{LF}}=100 \mathrm{kHz}$ (grey) and a mixer-based LSNA at $\mathrm{f}_{\mathrm{LF}}=10 \mathrm{MHz}$ (dots). The dynamic bias points are: $\left(\mathrm{V}_{\mathrm{g}}=-0.65 \mathrm{~V}, \mathrm{~V}_{\mathrm{d}}=\right.$ $6.4 \mathrm{~V})(\mathrm{a}),\left(\mathrm{V}_{\mathrm{g}}=-1.4 \mathrm{~V}, \mathrm{~V}_{\mathrm{d}}=7.9 \mathrm{~V}\right)(\mathrm{b}),\left(\mathrm{V}_{\mathrm{g}}=-0.98 \mathrm{~V}, \mathrm{~V}_{\mathrm{d}}=7.5 \mathrm{~V}\right)$ (c), and $\left(\mathrm{V}_{\mathrm{g}}=0.29 \mathrm{~V}, \mathrm{~V}_{\mathrm{d}}=3.1 \mathrm{~V}\right)(\mathrm{d})$. The frequency $\mathrm{f}_{\mathrm{RF}}$ is swept from $2 \mathrm{GHz}$ to $40 \mathrm{GHz}$.

\section{GAN CHARACTERIZATION}

In this Section we report the characterization results for a $0.25-\mu \mathrm{m} \mathrm{GaN}$ on $\mathrm{SiC}$ transistor by using dynamic-bias $\mathrm{S}$ parameters. Differently from the well-established GaAs technology, GaN-based transistors are more prone to dispersive effects [38], [39], [40], [43] which mainly impact transistor I-V characteristics and manifest as knee walkout and current collapse [14], [38], [39], [40]. Also, low-frequency variation of small-signal parameters is a manifestation of dispersive effects and it is typically captured by using either 
low-frequency VNA measurements [44] or pulsed Sparameter measurements [34], [35]. Dynamic-bias measurements, on the other hand, provide at the same time the dynamic I-V characteristics, which in fact coincide with the LSOP, and the small-signal parameters under large-signal operating condition and at the thermal and trap states set by the LSOP. Therefore one can characterize the aforementioned effects as a result of the same measurement. In fact, the measured LSOP provides direct information on the effect of dispersion on the dynamic I-V characteristics. The smallsignal parameters, measured along the time-varying LSOP, provide information on the effect of dispersion on highfrequency transistor behavior.

We performed dynamic S-parameter measurements with the mixer-based LSNA. We changed the LSOP by varying the quiescent point and by actively tuning the load impedance at $f_{L F}$. The frequency $f_{L F}$ was kept fixed at $10 \mathrm{MHz}$, which is above the cut-off frequency of dispersive effects [14]. This implies that both traps and temperature cannot follow the time-varying LSOP but remain frozen in a state determined by the bias point and by the shape of the load-line. In fact, even if the bias point was fixed, the load-line could instantaneously reach high-voltage regions and this could further enhance traps filling [26], [40], [45]. In Fig. 8a we show the load-lines corresponding to the measured LSOPs and in Fig. $8 \mathrm{~b}$ the dynamic-bias points corresponding to those load-lines. In Fig. $8 \mathrm{a}$ we also report dc measurements for the same device. Fig. 8 a provides us already with useful information on the device behavior. First, we can observe that, for all the load-lines, the instantaneous current follows very similar trajectories from linear to saturation region, regardless of the quiescent point where the load-lines were measured at and independently of the thermal and trap state which is different for each load-line. We only observe a slight difference between the static characteristic at $\mathrm{V}_{\mathrm{gdc}}=0 \mathrm{~V}$ (black dots in Fig. 8a) and the dynamic trajectory (dashed black line in Fig. 8a) depicted by the low-frequency load-lines. On the basis of these considerations, which can be readily derived as result of the proposed measurement technique, the selected $\mathrm{GaN}$ transistor does not show significant dispersion in the I-V characteristics and, therefore, we do expect to observe a moderate dispersive behavior in the high-frequency small-signal parameters.

We measured dynamic S-parameters, on top of each loadline in Fig. 8a, by sweeping the tickle frequency $f_{R F}$ from $1 \mathrm{GHz}$ to $20 \mathrm{GHz}$ with the tickle power set equal to $-30 \mathrm{dBm}$. The IF bandwidth was set equal to $1 \mathrm{kHz}$, which represented an acceptable trade-off between measurement time and noise level for the measurements that we performed. Next we derived envelopes from the measured RF intermodulation tones and use them to compute the dynamic-bias S-matrix by (1). As a result we obtained $\mathrm{S}$-parameters at each dynamic point in Fig. 8b and as function of $f_{R F}$.

In Fig. 9 we show the dynamic-bias $\mathrm{S}$-parameters at a point in the linear region on one of the load-lines measured at $\mathrm{V}_{\mathrm{gdc}}=$ $-6 \mathrm{~V}$ and $\mathrm{V}_{\mathrm{ddc}}=20 \mathrm{~V}$. The input-output trajectory corresponding to the selected load-line is reported in Fig. 9a. On that trajectory we selected the dynamic point at $\mathrm{V}_{\mathrm{g}}=$ -
$0.2 \mathrm{~V}$ and $\mathrm{V}_{\mathrm{d}}=4.7 \mathrm{~V}$, which is marked in Fig. 9a. In Fig. 9b we show the dynamic-bias S-parameters (black symbols) and the S-parameters measured with a VNA (grey line) with the device statically biased at $\mathrm{V}_{\mathrm{gdc}}=-0.2 \mathrm{~V}$ and $\mathrm{V}_{\mathrm{ddc}}=4.7 \mathrm{~V}$. In Fig. 9b we clearly observe a difference between static and dynamic-bias $S_{22}$. The in-depth understanding of the physical origin of this discrepancy is outside the scope of this paper. However, an intuitive explanation can be given by considering that, as $f_{R F}$ decreases, $S_{22}$ becomes directly linked to the transistor small-signal output conductance $\left(g_{d}\right)$ or the $Y_{22}$ parameter, which is the ac slope of the IV output characteristics at low frequencies. For the static bias measurement, the ac slope is measured at the thermal and trap states determined by dc voltages. On the other hand, under dynamic-bias conditions, the ac slope is measured at the thermal and trap states set by the low-frequency LSOP, which are different than those determined by a static bias. It is also noteworthy that the parameter $S_{11}$, which is directly linked to the transistor input capacitance, is practically identical in the two cases. This is coherent with the fact that, as experimentally demonstrated in many works, low-frequency dispersion has second order effects on transistor capacitances [5], [15], [19]-[22].

In Fig. 10 we compare, instead, the dynamic-bias Sparameters around the same dynamic point but on two LSOPs. In particular, we selected the dynamic point $\mathrm{V}_{\mathrm{g}}=-1 \mathrm{~V}$ and $\mathrm{V}_{\mathrm{d}}$ $=12 \mathrm{~V}$ on two load-lines whose input-output trajectories are shown in Fig. 10a and measured at $\mathrm{V}_{\mathrm{gdc}}=-2.75 \mathrm{~V}, \mathrm{~V}_{\mathrm{ddc}}=20 \mathrm{~V}$ (grey line) and $\mathrm{V}_{\mathrm{gdc}}=-6 \mathrm{~V}, \mathrm{~V}_{\mathrm{ddc}}=20 \mathrm{~V}$ (black line). As expected, the dynamic-bias parameters $\mathrm{S}_{11}, \mathrm{~S}_{12}$, do not exhibit any difference with respect to the LSOP. We observe a slight shift of the parameter $S_{21}$. Such a deviation is related to the different trap state associated to the two LSOPs that, as expected, causes a lower gain at lower $\mathrm{V}_{\text {gdc }}$. In addition, the drop of $S_{21}$ as $V_{\text {gdc }}$ decreases cannot be ascribed in this case to the slightly different thermal state determined by the average dissipated power across the two load-lines which was $545 \mathrm{~mW}$ for the load-line at $\mathrm{V}_{\mathrm{gdc}}=-2.75 \mathrm{~V}$ and $397 \mathrm{~mW}$ for the loadline at $\mathrm{V}_{\mathrm{gdc}}=-6 \mathrm{~V}$. If the drop were due to thermal effects, we should expect the $S_{21}$ on top of the load-line corresponding to the higher dissipated power to be lower than the $S_{21}$ on top of the other load-line. As regarding the parameters and $S_{22}$ we do not observe any significant shift in the two cases, especially at lower frequencies where this parameter is directly linked to the slope of the device output characteristics, which in turn determines the device output impedance. Since the selected dynamic-bias point $\left(\mathrm{V}_{\mathrm{g}}=-1 \mathrm{~V}, \mathrm{~V}_{\mathrm{d}}=12 \mathrm{~V}\right)$ lays in saturation region where the slope of the output characteristics is very low, the resulting device output impedance, which is linked to $\mathrm{S}_{22}$, is quite high and slightly sensitive to changes in traps and thermal state.

We want to highlight once again that the proposed measurement technique enables a more extensive study of dispersive effects by looking at the same time at the transistor dynamic I-V characteristics and at the high-frequency smallsignal parameters across a realistic LSOP.

Furthermore, for a fixed LSOP, as in the case of high- 
efficiency power-amplifiers, one can obtain the S-parameters at all the points of the LSOP and use them in the design phase [13], [25], [27]. Finally, although the proposed technique does not provide information on the actual traps and thermal states, by performing dynamic bias-measurements at different LSOPs one can obtain a data-set which can then be used to extract a nonlinear transistor model including dispersive effects as, for example, the one proposed in [15].

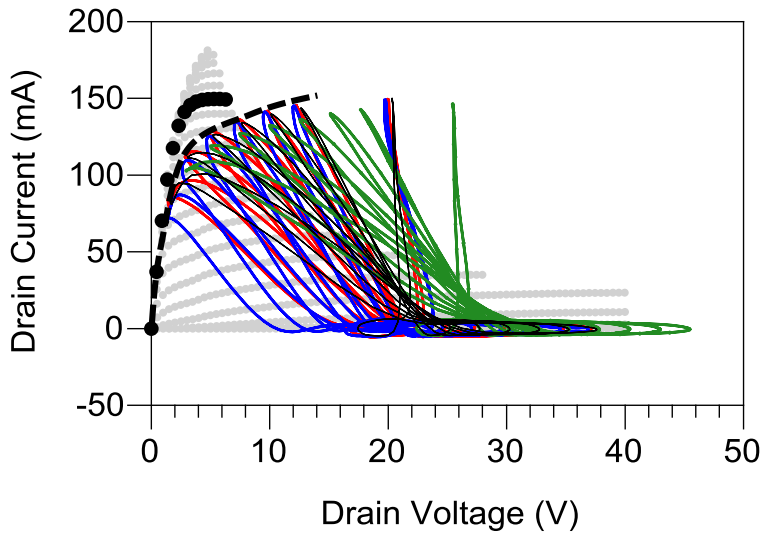

(a)

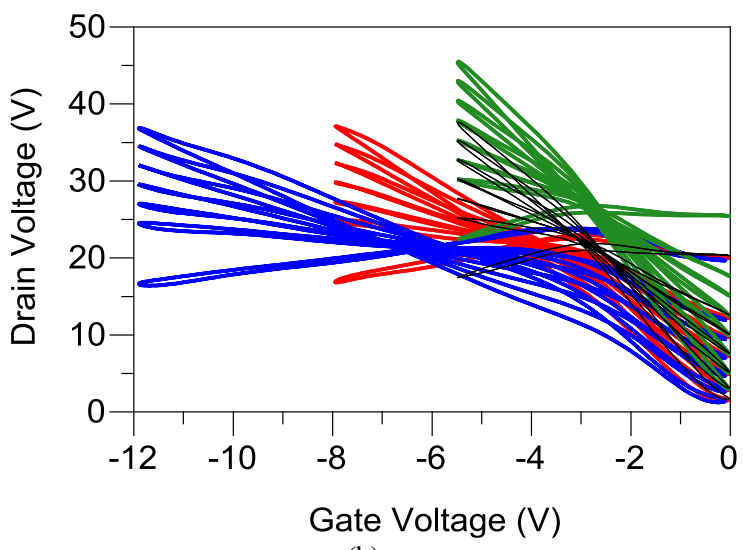

(b)

Fig. 8 Measured LSOPs of a $0.25-\mu \mathrm{m} \mathrm{GaN} \mathrm{HEMT} \mathrm{on} \mathrm{SiC} \mathrm{transistor.} \mathrm{Load-}$ lines (a) and corresponding dynamic-bias points (b) at: $\mathrm{f}_{\mathrm{LF}}=10 \mathrm{MHz}, \mathrm{V}_{\mathrm{gdc}}=-$ $2.75 \mathrm{~V}, \mathrm{~V}_{\mathrm{ddc}}=20 \mathrm{~V}$ (black continuous line), $\mathrm{V}_{\mathrm{gdc}}=-2.75 \mathrm{~V}, \mathrm{~V}_{\mathrm{ddc}}=25 \mathrm{~V}$ (green line in color version), $\mathrm{V}_{\text {gdc }}=-4 \mathrm{~V}, \mathrm{~V}_{\mathrm{ddc}}=20 \mathrm{~V}$ (red line in color version), and $\mathrm{V}_{\mathrm{gdc}}=-6 \mathrm{~V}, \mathrm{~V}_{\mathrm{ddc}}=20 \mathrm{~V}$ (blue line in color version). For each bias point the load was swept by active injection. In (a) we report also the measured dc characteristics (grey symbols). The dc characteristic at $\mathrm{V}_{\mathrm{gdc}}=0 \mathrm{~V}$ (black dots) and the dynamic trajectory at $\mathrm{V}_{\mathrm{g}}=0 \mathrm{~V}$ (dashed black line) are also highlighted in (a).

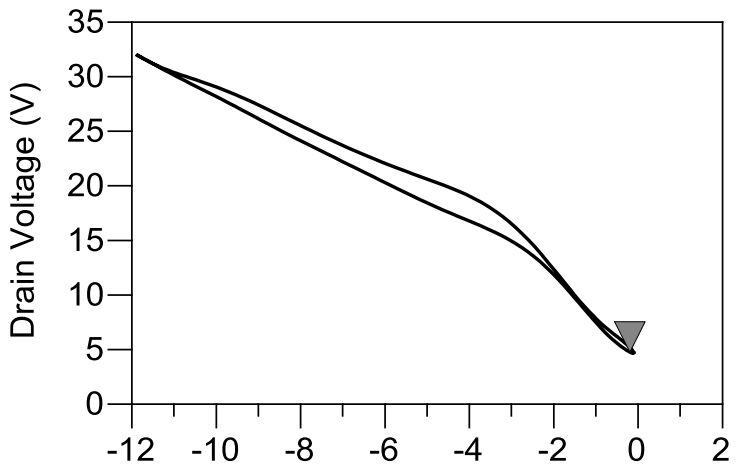

Gate Voltage (V)

(a)

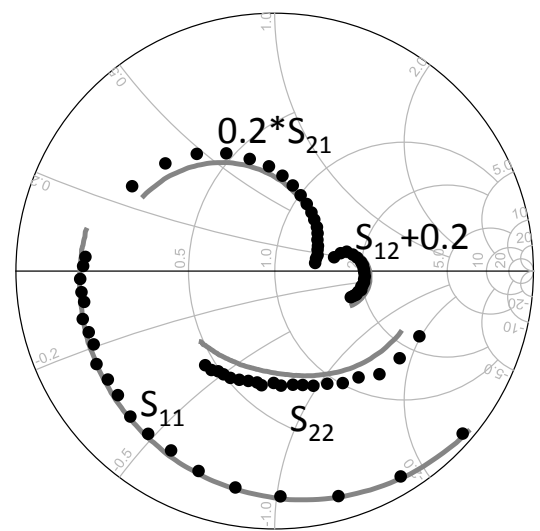

(b)

Fig. 9 Measured input-output LSOP trajectory (a) for a $0.25-\mu \mathrm{m}$ GaN HEMT on SiC transistor at $f_{\mathrm{LF}}=10 \mathrm{MHz}, \mathrm{V}_{\mathrm{gdc}}=-6 \mathrm{~V}$ and $\mathrm{V}_{\mathrm{ddc}}=20 \mathrm{~V}$. In (b) dynamic S-parameters as function of $\mathrm{f}_{\mathrm{RF}}$ from $2 \mathrm{GHz}$ to $20 \mathrm{GHz}$ around the dynamic point, indicated in (a) with triangle symbol, $\mathrm{V}_{\mathrm{g}}=-0.2 \mathrm{~V}$ and $\mathrm{V}_{\mathrm{d}}=$ $4.7 \mathrm{~V}$ (black symbols). Classical S-parameters measured with a $\mathrm{VNA}$ at $\mathrm{V}_{\mathrm{gdc}}=$ $-0.2 \mathrm{~V}$ and $\mathrm{V}_{\mathrm{ddc}}=4.7 \mathrm{~V}$ (grey line).

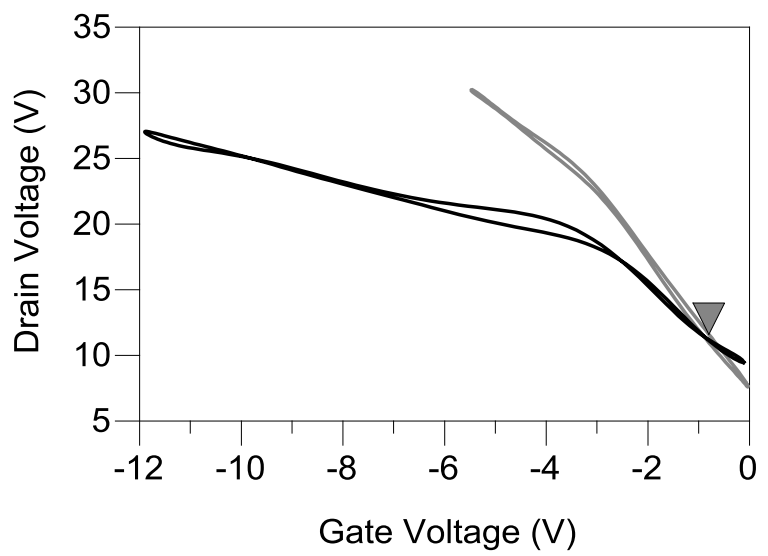

(a)

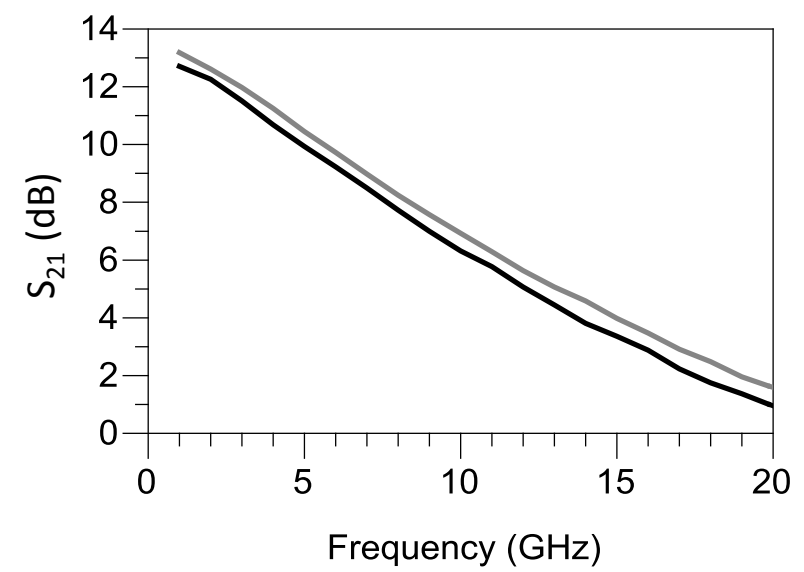

(b) 


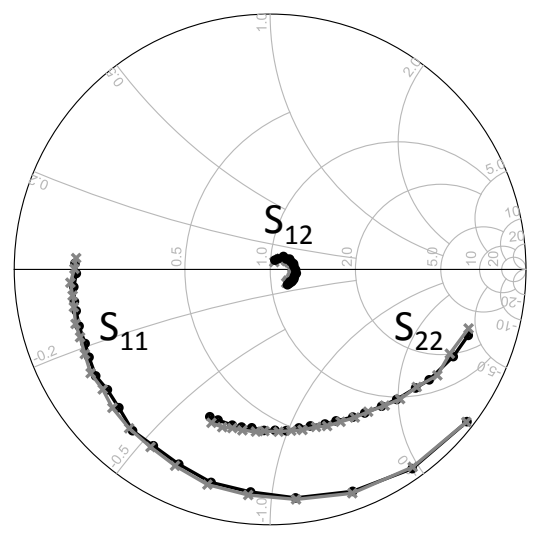

(c)

Fig. 10 Measured input-output LSOP trajectories (a) for a $0.25-\mu \mathrm{m} \mathrm{GaN}$ HEMT on $\mathrm{SiC}$ transistor at $\mathrm{f}_{\mathrm{LF}}=10 \mathrm{MHz}, \mathrm{V}_{\mathrm{gdc}}=-6 \mathrm{~V}, \mathrm{~V}_{\mathrm{ddc}}=20 \mathrm{~V}$ (black) and $\mathrm{V}_{\mathrm{gdc}}=-2.75 \mathrm{~V}, \mathrm{~V}_{\mathrm{ddc}}=20 \mathrm{~V}$ (grey). Dynamic S-parameters (b)-(c) as function of $\mathrm{f}_{\mathrm{RF}}$ from $2 \mathrm{GHz}$ to $20 \mathrm{GHz}$ around the dynamic point, indicated in (a) with triangle symbol, $\mathrm{V}_{\mathrm{g}}=-1 \mathrm{~V}$ and $\mathrm{V}_{\mathrm{d}}=20 \mathrm{~V}$.

\section{CONCLUSION}

We described a novel technique to obtain the scattering (S-) parameters of microwave transistors under large-signal operating conditions. The peculiarity of this measurement technique consists in providing at once the load-line at the transistor current-source, which coincides with the large-signal operating point and is measured at low frequencies, and, at the same time, the high-frequency S-parameters along that loadline. It relies on the dynamic-bias approach and, differently from classical multi-bias S-parameters, the device-under-test S-parameters are measured at all the dynamic-bias points of a time-varying large-signal operating point. Interestingly, these time-varying S-parameters can be used similarly as conventional S-parameters for characterization and modeling purposes, as they carry a great deal of information, especially when dealing with transistors whose behavior is affected by low-frequency dispersion.

\section{ACKNOWLEDGMENT}

G. Avolio is supported by FWO Vlaanderen, Belgium. G. Avolio and D. Schreurs would like to acknowledge Hercules foundation.

\section{REFERENCES}

[1] U. Lott, "Measurement of magnitude and phase of harmonics generated in nonlinear microwave two-ports," IEEE Trans. Microw. Theory Techn., vol. 37, no. 10, pp. 1506-1511, Oct. 1989.

[2] G. Kompa and F. Van Raay, "Error-corrected large-signal waveform measurement system combining network analyzer and sampling oscilloscope capabilities," IEEE Trans. Microw. Theory Techn., vol. 38, no. 4, pp. 358-365, Apr. 1990.

[3] A. Ferrero and U. Pisani, "An improved calibration technique for onwafer large-signal transistor characterization," IEEE Trans. Instr. Meas Tech., vol. 42, no. 2, pp. 360-364, Apr. 1993.

[4] T. Van den Broek and J. Verspecht, "Calibrated vectorial nonlinearnetwork analyzers," IEEE MTT-S International Microwave Symposium Digest, vol.2, pp. 1069-1072, May 1994.

[5] M. C. Curras-Francos , P. J. Tasker , M. Fernandez-Barciela , Y. Campos-Roca and E. Sanchez, "Direct extraction of nonlinear FET Q-V functions from time domain large signal measurements", IEEE Microw. Guided Wave Lett., vol. 10, no. 12, pp. 531-533, Dec. 2000.
[6] P. S. Blockley, D. Gunyan, and J. B. Scott, "Mixer-based, vectorcorrected, vector signal/network analyzer offering $300 \mathrm{kHz}-20 \mathrm{GHz}$," IEEE MTT-S Int. microw. Symp. Dig., pp. 1497-1500, Jun. 2005.

[7] D. Williams, P. Hale, and K. A. Remley, "The Sampling Oscilloscope as a Microwave Instrument," IEEE Microw. Mag., vol. 8, no. 4, pp. 59-68, Aug. 2007.

[8] M. Marchetti, J.M. Pelk, K. Buisman, W. Neo, M. Spirito, and L.C.N. de Vreede, "Active harmonic load-pull with realistic wideband communications signals," IEEE Trans. Microw. Theory Techn., vol. 56, no. 12, pp. 2979-2988, Dec. 2008.

[9] H. Qi, J. Benedikt, and P. J. Tasker, "Nonlinear data utilization: from direct data lookup to behavioral modeling," IEEE Trans. Microw. Theory and Techn., vol. 57, no. 6, pp.1425-1432, Jun. 2009.

[10] P. Roblin, D. E. Root, J. Verspecht, Y. Ko, and J. P. Teyssier, "New trends for the nonlinear measurement and modeling of high-power RF transistors and amplifiers with memory effects," IEEE Trans. Microw. Theory Techn., vol. 60, no. 6, pp. 1964-1978, Jun. 2012.

[11] V. Vadalà, A. Raffo, S. Di Falco, G. Bosi, A. Nalli, and G. Vannini, "A load-pull characterization technique accounting for harmonic tuning," IEEE Trans. Microw. Theory Techn., vol. 61, no. 7, pp. 2695-2704, Jul. 2013.

[12] V. Teppati, H. Benedickter, D. Marti, M. Garelli, S, Tirelli, R. Lovblom, R. Fluckiger, M. Alexandrova, O. Ostinelli, C.R. Bolognesi, "A W-band on-wafer active load-pull system based on down-conversion techniques," IEEE Trans. Microw. Theory Techn., vol. 62, pp. 148-153, Jan. 2014.

[13] A. Raffo, F. Scappaviva, and G. Vannini, "A New Approach to Microwave Power Amplifier Design Based on the Experimental Characterization of the Intrinsic Electron-Device Load Line," IEEE Trans. Microw. Theory Techn., vol. 57, no. 7, pp. 1743-1752, July 2009.

[14] A. Raffo, S. Di Falco, V. Vadalà, and G. Vannini, "Characterization of GaN HEMT low-frequency dispersion through a multiharmonic measurement system," IEEE Trans. Microw. Theory Techn., vol. 58, no. 9, pp. 2490-2496, Sep. 2010.

[15] A. Raffo, V. Vadalà, D. M. M.-P. Schreurs, G. Crupi, G. Avolio, A. Caddemi, and G. Vannini, "Nonlinear dispersive modeling of electron devices oriented to GaN power amplifier design," IEEE Trans. Microw. Theory Techn., vol. 58, no. 4, pp. 710-718, Apr. 2010.

[16] G. Pailloncy, G. Avolio, M. Myslinski, Y. Rolain, M. Vanden Bossche, and D. Schreurs, "Large-Signal network analysis including the baseband," IEEE Microw. Mag., vol. 12, no. 2, pp. 77-86, Apr. 2011.

[17] J. Xu, R. Jones, S. A. Harris, T. Nielsen, and D. E. Root, "Dynamic FET model - DynaFET - for GaN transistors from NVNA active source injection measurements," IEEE International MTT-S Microwave Symposium (IMS), pp. 1-3, Jun. 2014.

[18] S. Schafer, and Z. Popovic, "Multi-frequency measurements for supply modulated transmitters," IEEE Trans. Microw. Theory Techn., vol. 63, no. 9, pp. 2931-2941, Aug. 2015.

[19] G. Avolio, A. Raffo, I. Angelov, V. Vadalà, G. Crupi, A. Caddemi, G. Vannini, and D. Schreurs, "Nonlinear model for $40 \mathrm{GHz}$ cold-FET operation," in Proc. IEEE Int. Workshop Integr. Nonlinear Microw. Millimeter-Wave Circuits, pp. 1-3, Apr. 2014.

[20] V. Vadalà, A. Raffo, G. Vannini, G. Avolio and D. Schreurs, "GaN HEMT model extraction based on dynamic-bias measurements", 9th European Microwave Integrated Circuit Conference (EuMIC), pp. 206 209, Oct. 2014.

[21] G. Avolio, A. Raffo, I. Angelov, V. Vadalà, G. Crupi, A. Caddemi, G. Vannini, and D. Schreurs, "Millimeter-wave FET nonlinear modelling based on the dynamic-bias measurement technique," IEEE Trans. Microw. Theory Techn., vol. 62, no. 11, pp. 2526-2537, Nov. 2014.

[22] V. Vadalà, A. Raffo, G. Avolio, M. Marchetti, D. M. M. -P Schreurs, G. Vannini, "Extraction of accurate GaN HEMT model for high-efficiency power amplifier design", IEEE International MTT-S Microwave Symposium (IMS), pp. 1-4, May 2015.

[23] G. Crupi, D.M.M.-P. Schreurs, A. Caddemi, A. Raffo, and G. Vannini, "Investigation on the non-quasi-static effect implementation for millimeter-wave FET models," Int. Journ. RF and Microw. CAE, vol. 20, no. (1), pp. 87-93, Jan. 2010.

[24] A. Raffo, G. Avolio, V. Vadalà, D. M. M. -P. Schreurs, and G. Vannini, "A Non-quasi-static FET model extraction procedure using the dynamicbias technique," IEEE Microw. Wireless Comp. Letters, vol. 25, no. 12, pp. 841-843, Dec. 2015.

[25] H. Jang, P. Roblin, and Z. Xie, "Model-based nonlinear embedding for power amplifiers design," IEEE Trans. Microw. Theory and Techn., vol. 62, no. 9, pp. 1986-2002, Sep. 2014. 
[26] A. Raffo, G. Bosi, V. Vadalà, and G. Vannini, "Behavioral modeling of GaN FETs: a load-line approach," IEEE Trans. Microw. Theory and Techn., vol. 62, no. 1, pp. 73-82, Jan. 2014.

[27] P. Roblin, H-C. Chang, F. J. Martinez-Rodriguez, C. Xie, and J. I. Martinez-Lopez, "On the Design of GaN Chireix Power Amplifiers using an Embedding Device Model," International Journal of Numerical Modelling: Electronic Networks, Devices and Fields, doi: 10.1002/jnm.2148, 2016

[28] F. Verbeyst and M. V. Bossche, "VIOMAP, the S-parameter equivalent for weakly nonlinear RF and microwave devices," in IEEE MTT-S Int. Microwave Symp. Dig., May 1994.

[29] J. Martens, and P. Kapetanic, "Probe-tone S-parameter measurements," IEEE Trans. Microw. Theory Techn., vol. 50, no. 9, pp. 2076-2082, Sep. 2002.

[30] T. Gasseling, D. Barataud, S. Mons, J.M. Nebus, J.P. Villotte, J.J. Obregon, and R. Quere, "A new characterization technique of "Four hot S parameters" for the study of nonlinear parametric behaviors of microwave devices," IEEE MTT-S IMS, pp. 1663-1666, Jun. 2003

[31] T. Gasseling, D. Barataud, S. Mons, J.M. Nebus, J.P. Villotte, J.J. Obregon, and R. Quere, "Hot small-signal S-parameter measurements of power transistors operating under large signal conditions in a load-pull environment for the study of nonlinear parametric interactions," IEEE Trans. Microw. Theory Techn., vol. 52, no. 3, pp. 805-812, Mar. 2004.

[32] J. Verspecht, D. Barataud, J.P. Teyssier, and J.M Nébus, "Hot Sparameter techniques: $6=4+2$," 66th ARFTG Conference, Dec. 2005

[33] J. Verspecht, D.F. Williams, D. Schreurs, K.A. Remley, and M.D. McKinley, "Linearization of large-signal scattering functions," IEEE Trans. Microw. Theory and Techn., vol. 53, no. 4, pp. 1369-1376, Apr. 2005.

[34] J.P. Teyssier, P. Bouysse, Z. Ouarch, D. Barataud, T. Peyretaillade, and R. Quere, "40 GHz/150-ns versatile pulsed measurement system for microwave transistor isothermal characterization," IEEE Trans. Microw. Theory and Techn., vol. 46, no. 12, pp. 2043-2052, Dec. 1998.

[35] J. Martens, "Pulsed S-parameter measurements: on resolution, duration, and uncertainty," IEEE International Conference on Microwaves, Communications, Antennas and Electronics Systems, pp. 1-5, Oct. 2013.

[36] J. Verspecht, and D. E. Root, "Poly harmonic distortion modeling," IEEE Microw. Magazine, vol. 7, no. 3, pp. 44-57, Jun 2006.

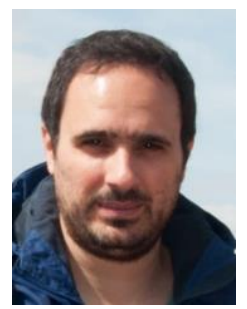

Gustavo Avolio (M'12) was born in Cosenza, Italy, in 1982. He received the MSc. in electronic engineering from the University of Calabria, Italy, in 2006. In 2012 he obtained the Ph.D. in electronic engineering from $\mathrm{KU}$ Leuven, Belgium. $\mathrm{He}$ is currently a post-doctoral researcher supported by FWO Vlaanderen, Belgium. In 2013 and 2014 he has been a visiting scientist at the National Institute of Standards and Technology (NIST) in Boulder, USA. Since 2009 he has often been a visiting scientist at the University of Ferrara, Italy. His research work focuses on large-signal measurements and nonlinear modeling of advanced microwave devices.

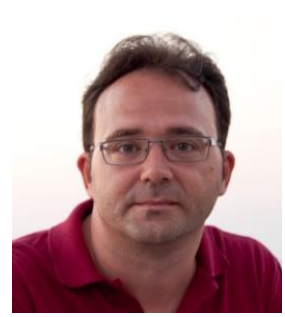

Antonio Raffo (S'04-M'07) was born in Taranto, Italy, in 1976. He received the M.S. degree (with honors) in electronic engineering and Ph.D. degree in information engineering from the University of Ferrara, Ferrara, Italy, in 2002 and 2006, respectively.

Since 2002, he has been with the Engineering Department, University of Ferrara, where he is currently a Research Associate and teaches courses in semiconductor devices and electronic instrumentation and measurement. His research activity is mainly oriented to nonlinear electron device characterization and modeling and circuit-design techniques for nonlinear microwave and millimeter-wave applications. Dr. Raffo has coauthored over 100 publications in international journals and conferences and has coedit the book entitled "Microwave Wireless Communications: From Transistor to System Level" (Academic Press, Oxford, UK, 2016).

Dr. Raffo is a member of the Technical Programme Committee of the
[37] M. Myslinski, F. Verbeyst, M. V. Bossche, and D. Schreurs, "S-functions behavioral model order reduction based on narrowband modulated largesignal network analyzer measurements," in Proc. 75th Microwave Measurements Conf. (ARFTG), pp. 1-6, May 2010.

[38] A. E. Parker and J. G. Rathmell, "Measurement and characterisation of HEMT dynamics," Asia-Pacific Microwave Conference Proceedings pp. 846-849, Dec. 2000.

[39] O. Jardel et al., "An electrothermal model for $\mathrm{AlGaN} / \mathrm{GaN}$ power HEMTs including trapping effects to improve large-signal simulation results on high VSWR," IEEE Trans. Microw. Theory and Techn., vol. 55, no. 12, pp. 2660-2669, Dec. 2007.

[40] A. Santarelli, D. Niessen, R. Cignani, G. Gibiino, P.A Traverso, C. Florian, D. M. M. -P. Schreurs, and F. Filicori, "GaN FET nonlinear modeling based on double pulse I/V characteristics," IEEE Trans. Microw. Theory and Techn., vol. 62, no. 12, pp. 3262-3273, Dec. 2014.

[41] I. Angelov, N. Rorsman, J. Stenarson, M. Garcia, and H. Zirath, "An empirical table-based FET model," IEEE Trans. Microw. Theory and Techn., vol. 47, no. 12, pp. 2350-2357, Dec. 1999.

[42] G. Avolio, D. Schreurs, B. Nauwelaers, A. Raffo, and G. Vannini, "Bias and frequency dispersion of dynamic I-V characteristics in microwave transistors," European Microwave Integrated Circuits Conference (EuMIC), pp. 93-96, Oct. 2011.

[43] V. I. Cojocaru and T. Brazil, "A scalable general-purpose model for microwave FET's including DC/AC dispersion effects," IEEE Trans. Microw. Theory and Techn., vol. 45, pp. 2248-2255, Dec. 1997.

[44] J.C. Nallatamby, R. Sommet, S. Laurent, M. Prigent, R. Quere, and O. Jardel, "A microwave modeling oxymoron?: low-frequency measurements for microwave device modeling," IEEE Microw. Mag., vol. 15, no. 4, pp. 92-107, Jun. 2014.

[45] A. S. Roy and C. C. Enz, "Analytical modeling of large-signal cyclostationary low-frequency noise with arbitrary periodic input," IEEE Transactions Electron Devices, Vol. 54, No. 9, pp. 2537-2545, Sep. 2007

IEEE International Workshop on Integrated Nonlinear Microwave and Millimetre-wave Circuits (INMMiC) and serves as an associate editor of the International Journal of Numerical Modelling: Electronic Networks, Devices and Fields. He also served as Technical Programme Committee chair for the IEEE INMMiC conference, Leuven, Belgium, 2014. Dr. Raffo is a member of the IEEE Microwave Measurement Technical Committee (MTT-11).

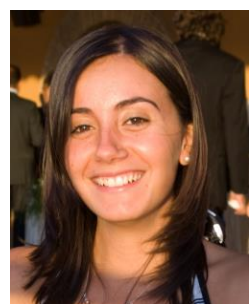

Valeria Vadalà (S'07-M'11) was born in Reggio Calabria, Italy, in 1982. She received the M. S. degree (with honors) in electronic engineering from the "Mediterranea" University of Reggio Calabria, Reggio Calabria, Italy, in 2006 and the Ph.D. degree in information engineering from the University of Ferrara, Ferrara, Italy, in 2010. Dr. Vadalà is currently with the Department of Engineering, University of Ferrara as Postdoctoral Researcher. Her research interests include nonlinear electron-device characterization and modeling and circuit-design techniques for nonlinear microwave and millimeter-wave applications.

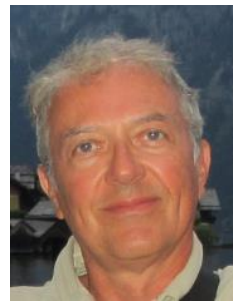

Giorgio Vannini (S'87-M'92) received the Laurea degree in electronic engineering and Ph.D. degree in electronic and computer science engineering, from the University of Bologna, Bologna, Italy. In 1993, he joined the Department of Electronics, University of Bologna, as a Research Associate. From 1994 to 1998, he was with the Research Centre on Electronics, Computer science and Telecommunication Engineering, National Research Council (CSITE), Bologna, Italy, where he was responsible for MMIC testing and the Computer-Aided Design (CAD) Laboratory. In 1998, he joined the University of Ferrara, Ferrara, Italy, as an Associate Professor, and since 2005, as a Full Professor of electronics. He was Head of the Engineering 
Department from 2007 to 2015. During his academic career he has coauthored over 250 articles devoted to electron device modeling, computer aided design techniques for MMICs, and nonlinear circuit analysis and design. $\mathrm{He}$ is a cofounder of the academic spinoff Microwave Electronics for Communications (MEC).

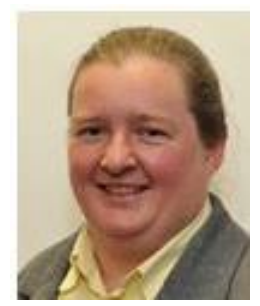

Dominique M. M.-P. Schreurs (S'90-M'97-SM'02Fellow) received the M.Sc. degree in electronic engineering and $\mathrm{Ph} . \mathrm{D}$. degree from the University of Leuven (KU Leuven), Belgium.

She is now a Full Professor with KU Leuven. She has been a Visiting Scientist with Agilent Technologies, ETH Zürich, and the National Institute of Standards and Technology (NIST). Her main research interests concern the (non)linear characterization and modeling of active microwave devices, and (non)linear circuit design for telecommunications and biomedical applications.

Prof. Schreurs is serving on the AdCom of the MTT Society. She is an IEEE Fellow, past MTT-S Distinguished Microwave Lecturer, and presently also editor of IEEE Trans. Microwave Theory and Techniques. She serves as VicePresident on the Executive Committee of the ARFTG organization, and was general chair of the 2007 and 2012 Spring ARFTG Conference. Prof. Schreurs was co-chair of the European Microwave Conference (EuMC) in 2008. 